\title{
A Collective Case Study: Parent-Child Sexual Health Communication of Current and Former Teen Parents in Lawrence County, Indiana
}

Aislinn Betts ${ }^{1}$, Allison Greene ${ }^{2}$, Catherine Sherwood-Laughlin ${ }^{2}$

${ }^{1}$ Indiana University School of Medicine; ${ }^{2}$ Indiana University School of Public Health, Department of Applied Health Science

\section{Background/Objective:}

In Lawrence County, Indiana, the birth rate for females ages $15-19$ is 32.2 births per 1,000, which is significantly higher than the national average of 18.8. Project UNITE, a collaboration between the Lawrence County Pregnancy Coalition and the IU School of Public Health, aims to address this issue through a multifaceted evidence-based intervention. Since parent-child communication shapes values and behaviors, a collective case study was conducted with current and former teen parents to explore their perceptions of sexual health communication with their parents and, if applicable, with their children.

Methods:

Of the 58 semi-structured telephone interviews conducted through Project UNITE, eight were selected for this study based on transcript availability and identification as a current teen parent (2) or former teen parent (6). All participants recalled whether they had sexual health conversations with their parents and the extent of the discussions. Five shared experiences talking with their children. Deductive and inductive approaches were used to generate themes, which were then analyzed.

Results:

Most participants (7 of 8 ) reported little to no communication about sexual health with their parents due to a lack of comfortability, limited desire, and poor relationships. In contrast, all respondents with children over the age of five (5 of 5 ) reported open and frequent conversations with them. Several (3 of 8 ) recommended providing parents with resources about initiating discussions, and some suggested ( 2 of 8 ) a community program to promote sexual health communication.

\section{Conclusions/Potential Impact:}

The results revealed that while teen parents experienced a lack of sexual health conversations with their parents, they favored open and honest communication with their children. Barriers related to comfortability and knowledge could be alleviated through parental resources and parent-child programs. Medical professionals play a role in this solution by encouraging conversations about sexual health and engaging in educational programs. 